\title{
Study of the mechanical properties of sheet metals drawn through drawbeads
}

\author{
Harald Schmid* and Marion Merklein \\ Institute of Manufacturing Technology, Friedrich-Alexander-Universität Erlangen-Nürnberg (FAU), Egerlandstr. 13, \\ 91058 Erlangen, Germany
}

Received: 17 February 2019 / Accepted: 14 May 2019

\begin{abstract}
The use of modern materials leads to a need for detailed knowledge of the material flow. Drawbeads are one common way to control serial forming processes. Although they are already well investigated, the effect on the resulting mechanical properties after a drawbead passage is not analysed in detail yet. This work is showing the influence of a drawbead geometry used in deep drawing on typical mechanical properties. Therefore, different sheet metal materials are preloaded in a modified strip drawing test with commonly used drawbeads. In testing, three different levels of pressure between 2.5 MPa and 7.5 MPa and of drawing speed between $10 \mathrm{~mm} / \mathrm{s}$ and $50 \mathrm{~mm} / \mathrm{s}$ are combined to nine variations and are examined. Afterwards, specimens are cut out by a laser cutting machine of the drawn strips. Those specimens are then tested with the use of an optical measurement system. Results are discussed in relation to blankholder pressure, drawing velocity and drawbead geometry to work out the main effects. Overall it can be stated, that variations of blank holder pressure and drawbead height lead to significant changes for the material properties. A variation of the drawing velocity in the observed range does not show significant effects.
\end{abstract}

Keywords: Deep drawing / hardening / sheet metal / drawbead

\section{Introduction}

Deep drawn parts are more complex in geometry and material these days than in the past, according to Barthau et al. [1]. This requires an accurate knowledge and prediction of the material flow to control it and to achieve satisfying product quality. While modifications of the blank holder force or the lubrication system are options to control forming processes, drawbeads are also a popular way to improve the material flow by a modification of the induced forces. Drawbeads are already examined in detail regarding retention forces but not when considering modified mechanical properties of the sheet metal after a drawbead passage. This causes the necessity for a more detailed investigation of the impact of drawbeads on the used sheet material itself. At the moment, a lot of conventional steel materials in the automotive industry are replaced with high strength steel or aluminium alloys for the reason of light weight design, according to Mohrbacher et al. [2]. Because of the high formability and their high strength, the sheet thickness and therefore the overall weight can be reduced, what is also described by Bleck and Ratte [3].

In the past, different authors have already investigated drawbeads and their effects on the forming process.

\footnotetext{
* e-mail: harald.schmid@fau.de
}

Liu et al. could already successfully predict in [4] the forming and springback behaviour of sheet material undergoing multiple bending-unbending cycles, as they appear in a drawbead. A FE simulation combined with a non-linear isotropic/kinematic hardening model shows almost the same results compared to the conducted experiments. According to their findings, the predicted results are highly influenced by the used hardening model and the results present a decreasing accuracy with more bending-unbending cycles compared to the experimental data. That's another reason, why sheet metal hardening after drawbeads should be examined. In [5], the hardening of sheet metal was examined for two different levels of blank holder pressure and in three layers over the thickness by the authors. It could be demonstrated, that a drawbead leads to different hardening levels in the sheet layers and in drawing direction after the passage what is followed by a non-homogeneity over the thickness. Also, results from a modified strip drawing test with a drawbead geometry are compared to results from a deep drawing process. In addition, in [6] the influence of drawbeads on material hardening was also investigated on the upper and lower side in drawing direction. Additionally, the measured strain development was correlated with the hardening behaviour and an overall hardening as well as a rising accumulated strain was described. 
Halkaci et al. [7], that a deep drawing process is changed with drawbeads and improves the limiting drawing ratio by up to $10 \%$ for this process. This also indicates a shift in mechanical properties for the use of drawbeads. Samuel develops a numerical model in [8] to calculate forces and stresses during a drawbead passage and compares these findings with his experimental data. A new material model is used, which is also based on the strain hardening exponent $\mathrm{n}$ from tensile tests. The numerical results are found in a good agreement with the experimental data in between $8 \%$ standard deviation. It is also observed, that the drawbead geometry and friction coefficient $\mu$ highly affect the retention and pressure forces for the calculations in a process with drawbeads. Looking on the used materials DC04, DP800 and AA6014, also some investigations have been conducted regarding their hardening behaviour. Silvestre et al. [9] investigated hardening behaviour of different steel grades. It was shown, that mild steels like DC04 are presenting a cyclic hardening behaviour when they are loaded and reverse loaded again and again. In comparison, the advanced high strength steels like the investigated DP800 show cyclic softening behaviour. Also, the mild steel was increasing its yield strength with every cycle, while the advanced high strength steels showed a constant yield strength value with every cycle. This can be seen as a saturation and a stable microstructure, according to Silvestre [9]. Finally, the two used steel grades already show a different hardening behaviour, what obviously also has effects when considering the sheet metal after a drawbead passage. Additionally, Schreijäg [10] examined in 2013, that macroscopic forming conditions of DC04 mainly depend on the anisotropy of the texture of the used sheet metal. Connecting this with the deep drawing process through drawbeads, it could be possible to achieve different mechanical properties after a drawbead passage, e.g. depending on the rolling direction.

The aluminium alloy AA6014-T4, according to Bloeck [11], is mainly used because of its good formability, an excellent age hardenability as well as the stability of the mechanical properties during room temperature storage. In the analysis of an advanced necking criterion for nonlinear strain paths for AA6014, Drotleff et al. [12] found that the strain hardening exponent $\mathrm{n}$ from AA6014 is reduced from 0.25 to 0.05 for a true effective pre strain of 0.15 . According to [12], this also effects the failure behaviour and especially the FLC.

Next to the work hardening behaviour, failure of sheet metal is also highly significant in deep drawing processes. Bressan et al. [13] examined AA6014 sheets and found that pre-stretching alloy in uniaxial or biaxial direction reduces residual FLC for AA6014. The reduction was also linear connected to the pre-stretching level. Saxena et al. [14] evaluated bending limit curves for AA6014 and stated that they were at a higher level compared to conventional FLC. This is also important when using drawbeads with its bending component.

Kitting et al. examined in [15] combinations of stretching and bending in complex deep drawing processes. The authors show a very sophisticated strain evolution and highly non-linear strain paths for the analysed area. For a drawbead, further complexity is expected because of the alternating bending with overlying tensions. For this complex loading condition, failure also is examined. One common failure criteria is the Forming Limit Curve (FLC) as one of the first described by Keeler [16], which is also normed internationally in DIN EN ISO 12004-2:2009-02 [17]. It was indicated, that failure behaviour is influenced by pre-straining and strain paths. Initial and pre-strained materials were already examined in 1975 by Müschenborn and Sonne [18]. Their results showed basically, that the FLC and therefore failure behaviour is mainly dependent on the strain path and especially on the amount of prestraining. By Denninger et al. [19], a so called Bending Limit Curve (BLC) was developed to describe failure in case of bending, what is also part of a drawbead passage. Werber et al. [20] were able to show the effect of different linear pre-stretching methods on the forming limit diagram and therefore the failure behaviour. As the preloading in a drawbead is even more complex according to [6], a significant effect on the failure behaviour like fracture strains is also expected.

Bending, pre-strains and strain paths are also important for drawbead processes, therefore it needs to be taken into account. All presented findings can be interpreted evidence for significant changes in mechanical properties after a drawbead passage. Such a shift can lead to incorrect determination of material models and poor numerical calculations what finally leads to bad forming results. This makes further and more detailed investigations of drawbead processed parts necessary. Still, there are insufficient investigations about the influence of different process parameters on the material characteristics in drawbeads. This testing will help to determine the behaviour of different sheet metal materials under varying conditions in the drawbead passage and to improve the deep drawing process itself.

\section{Materials}

Because of their use in the automotive industry, a conventional steel, a high-strength steel and an aluminium alloy will be examined after a drawbead passage. Therefore, DC04, a mild steel is used very commonly in deep drawing processes. Also, an advanced high strength steel HCT780X, also called DP800, will be observed as a modern lightweight-material. It is also often used in the automotive industry in the last years. Additionally, the 6000-series aluminium alloy AA6014 in T4 state is examined, what means it was annealed and naturally aged to a stable state. The alloy is widely used in structural and bodyshell components in the automotive industry [11], as aluminium is a modern lightweight material with a lower density and therefore often a lower weight.

The mild steel DC04 offers a high formability in forming processes and is tested in an initial thickness of $t_{0}=1.0 \mathrm{~mm}$. The initial tensile strength is $\mathrm{TS}=314.4 \mathrm{MPa}$, the yield strength $\mathrm{YS}=162.1 \mathrm{MPa}$, the uniform elongation $\varepsilon_{\mathrm{u}}=$ $25.9 \%$ and the fracture strain $\varepsilon_{f}=44.2 \%$. DP800 presents a significant higher tensile strength of $\mathrm{TS}=817.9 \mathrm{MPa}$ and the yield strength $\mathrm{YS}=516.1 \mathrm{MPa}$. The uniform elongation of DP800 is about the half of DC04 and amounts with 


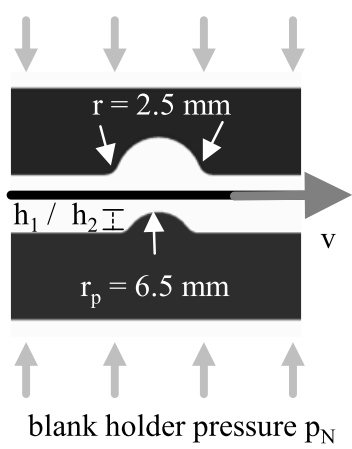

a)

Fig. 1. Strip drawing test with geometry and drawbead height $h_{1}$ and $h_{2}$ according to [21] in process illustration (a) and used test bed with clamping and drawing unit (b).

$\varepsilon_{u}=12.9 \%$ while the fracture strain is about $\varepsilon_{f}=17.4 \%$. AA6014 provides the tensile strength $\mathrm{TS}=236.1 \mathrm{MPa}$ and the yield strength $\mathrm{YS}=131.0 \mathrm{MPa}$. The uniform elongation and the fracture strain result in $\varepsilon_{u}=20.0 \%$ and $\varepsilon_{f}=24.0 \%$.

For material hardening, the strain hardening exponent also is quite important. For DP800 it is about $n_{\mathrm{DP} 800}=0.27$ while DC04 has an exponent of $n_{\mathrm{DC} 04}=0.16$, what is nearly the half. The aluminium alloy AA6014 shows a hardening exponent of $n_{\mathrm{AA} 6014}=0.26$ and about the same the highstrength steel DP800. In this work, these material parameters in the initial state will be used to quantify the changes of the material parameters after a drawbead passage.

\section{Experimental setup}

Especially standardized material characterization techniques seem to be suitable to compare results of preloaded parts to their initial state. Within these investigations, the uniaxial tensile test is used to investigate the influence of drawbeads on sheet metal parts. The tensile test is an international standardized material test. Also, it is possible to determine well known and meaningful parameters like the tensile strength TS, the yield strength YS, the uniform strain $\varepsilon_{u}$ or the fracture strain $\varepsilon_{f}$.

The sheet metal strips with a size of $700 \times 50 \mathrm{~mm}^{2}$ need to pass the drawbead passage where they are preloaded. Therefore, a modified strip drawing test is used, that was also described in [6] and is shown in detail in Figure 1. The used drawbead geometry is built according to the Numisheet 2008 benchmark [21] and has a peak radius of $r_{p}=6.5 \mathrm{~mm}$, a drawbead height $\mathrm{h}$ of either $h_{1}=3.6 \mathrm{~mm}$ or $h_{2}=5.0 \mathrm{~mm}$. This is commonly used to vary the retention forces. The running in and running out radii are set to $r=2.5 \mathrm{~mm}$. The drawbead tools are built into a strip drawing test machine, as can be seen in Figure 1, where the schematic process is illustrated. For preloading of materials with a thickness higher than $t_{0}=1.0 \mathrm{~mm}$, the die would need to be adapted according to $[21]$.

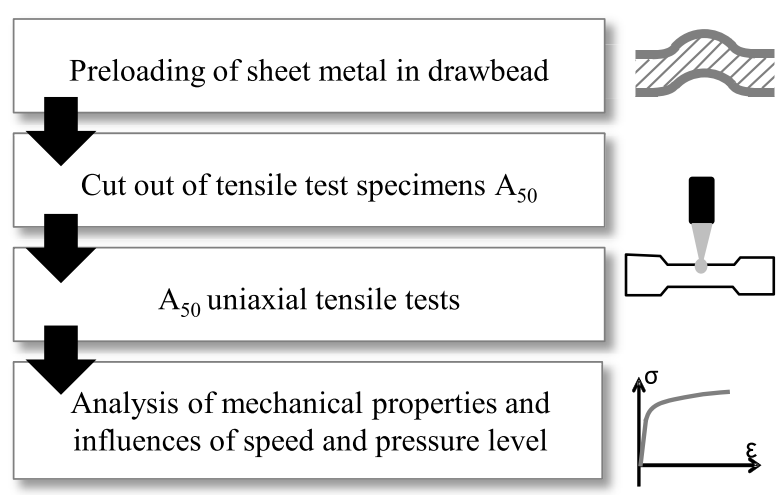

Fig. 2. Methodology used for tensile test examination of preloaded specimens after drawbead passage.

After being lubricated with deep-drawing oil Multidraw KTL N 16 (Zeller + Gmelin GmbH), the metal strips are subsequently drawn through the drawbead. This can be done with varying velocities of $v=10 \mathrm{~mm} / \mathrm{s}, 30 \mathrm{~mm} / \mathrm{s}$ and $50 \mathrm{~mm} / \mathrm{s}$ while the blankholder pressure is varied between $p_{\mathrm{N}}=2.5 \mathrm{MPa}, 5.0 \mathrm{MPa}$ and $7.5 \mathrm{MPa}$. During this process, the velocity $v$ and the normal pressure $p_{\mathrm{N}}$ are controlled automatically and kept constant. After that, $\mathrm{A}_{50}$ tensile test specimens according to DIN EN ISO 6892-1 [22] are laser cut out of the preloaded and deformed metal strips. Therefore, the strips have to be fixed by a tool on the laser machine bed because of their deformation to cut the correct specimen geometry. The preloading as well as the cut out is executed in $0^{\circ}$ to the rolling and drawing direction. Finally, five specimens were tensile tested for every variation $(n=5)$ on a universal testing machine Z100 (Zwick GmbH \& Co. KG) based on DIN EN ISO 6892-1 [22] and by using the optical measurement system ARAMIS (GOM GmbH). The strain rate was set to $\dot{\varepsilon}=0.41 / \mathrm{s}$ for steel according to SEP 1240 [23] and $\dot{\varepsilon}=0.6671 / \mathrm{s}$ for the aluminium alloy according to VDA 239-300:2015 [24].

The elongation was evaluated and averaged for every specimen over the measurement area with a length of $l_{0}=50 \mathrm{~mm}$. The process and methodology is also presented in Figure 2.

Because of their importance for the deep drawing process, the influence of the blank holder pressure $p_{\mathrm{N}}$, the velocity $v$ and the drawbead height $\mathrm{h}$ in a drawbead are examined. The results are pointed out in the next section.

\section{Results}

In this section, results of the conducted tensile tests will be described in detail and in dependency of the varied parameters.

\subsection{Sheet thickness after drawbead passage}

After drawing the metal strips through the drawbead, every sheet metal has a different thickness depending on the material and the varied parameters in this process. This 


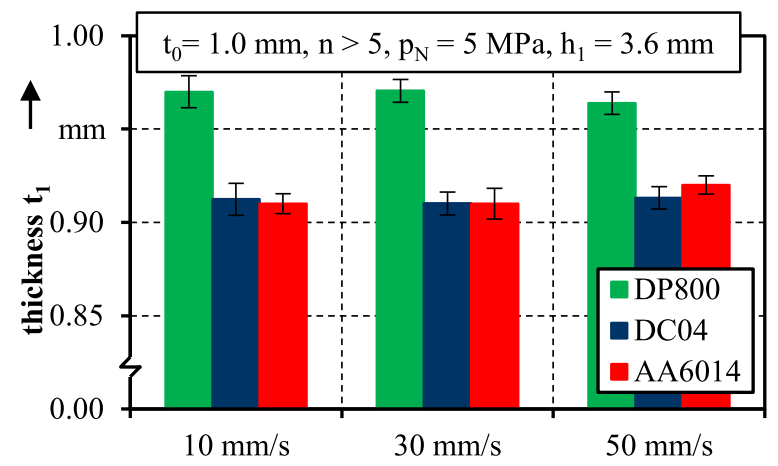

Fig. 3. Strip thickness after drawbead passage with $h_{1}=3.6 \mathrm{~mm}$, a constant blankholder pressure $p_{\mathrm{N}}=5 \mathrm{MPa}$ and variation of drawing velocity between $v=10 \mathrm{~mm} / \mathrm{s}$ and $50 \mathrm{~mm} / \mathrm{s}$.

can be seen in Figure 3, where the thickness results for preloaded strips with a constant blankholder pressure of $p_{\mathrm{N}}=5 \mathrm{MPa}$ and a varying velocity are presented. These changes need to be considered in the tensile tests for the analysis of the stress.

It can be seen in general, that the thinning is more obvious for $\mathrm{DC} 04$ and $\mathrm{AA} 6014$ with a remaining thickness of about $t_{1}=0.9 \mathrm{~mm}$ in comparison to DP800 with a remaining thickness over $t_{1}=0.95 \mathrm{~mm}$. The effect of the velocity on the sheet thickness $t_{1}$ at a constant pressure $p_{\mathrm{N}}$ is in between the standard deviation and therefore not significant. It was already shown by the authors in [25], that for DC04 and DP800 at a blankholder pressure of $p_{\mathrm{N}}=2.5 \mathrm{MPa}$ and $7.5 \mathrm{MPa}$, no effect on the thickness was visible. Therefore, any variation of the drawing velocity in a drawbead passage comparable to Numisheet 2008 in between $10 \mathrm{~mm} / \mathrm{s}$ and $50 \mathrm{~mm} / \mathrm{s}$ is not expected to have an effect for the thinning behaviour itself.

In Figure 4, the thickness after a drawbead passage for the constant velocity of $v=50 \mathrm{~mm} / \mathrm{s}$ is shown depending on the drawbead height $\mathrm{h}$ and the blankholder pressure $p_{\mathrm{N}}$. It can be seen, that an increase in the blankholder pressure leads to thinner sheet metal strips after the drawbead. For $h_{1}=3.6 \mathrm{~mm}$ and the highest pressure of $p_{\mathrm{N}}=7.5 \mathrm{MPa}$, the material DP800 still has a thickness of $t_{1}=0.95 \mathrm{~mm}$, DC04 and AA6014 only about $t_{1}=0.9 \mathrm{~mm}$. Using the higher drawbead with the height $h_{2}=5.0 \mathrm{~mm}$ leads to a higher reduction of the thickness. For $p_{\mathrm{N}}=7.5 \mathrm{MPa}$, further thinning with $t_{1}=0.85 \mathrm{~mm}$ for DC04 and AA6014 and $t_{1}=0.88 \mathrm{~mm}$ for DP800 is visible. A saturation level in the thinning for the mild steel DC04 between $p_{\mathrm{N}}=5.0 \mathrm{MPa}$ and $7.5 \mathrm{MPa}$ and the drawbead $h_{2}=5.0 \mathrm{~mm}$ is evident. According to the thickness reduction results in Figures 3 and 4 , special changes already become visible and different trends can be indicated.

Further investigations were shown in [25]. Also more experimental investigations under varying parameters have been conducted. The influence of the velocity and the blank holder pressure in the strip drawing test with drawbead was analysed in the tensile test setup.

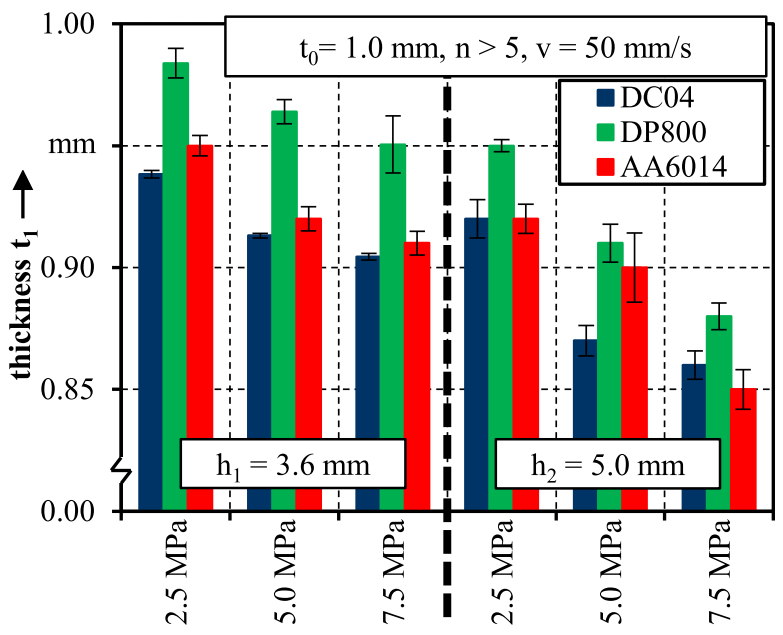

Fig. 4. Strip thickness after drawbead for a constant velocity of $v=50 \mathrm{~mm} / \mathrm{s}$ and drawbeads with $h_{1}$ and $h_{2}$ and the variation of the blankholder pressure $p_{\mathrm{N}}=2.5-7.5 \mathrm{MPa}$.

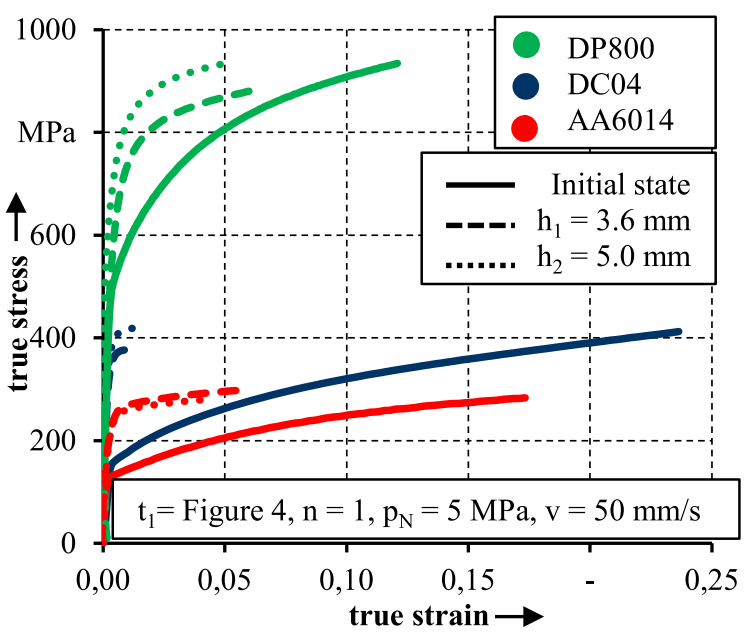

Fig. 5. True stress-true strain diagram of initial and preloaded specimens for all materials and drawbead heights $h_{1}$ and $h_{2}$ $\left(p_{\mathrm{N}}=5.0 \mathrm{MPa}, v=50 \mathrm{~mm} / \mathrm{s}\right)$.

\subsection{Tensile test results after drawbead preloading}

To overlook the changes in the material characteristics, a true stress-true strain diagram of all three materials is drawn in Figure 5. It shows one representative curve of $n=5$ tested specimens for DC04, DP800 and AA6014 in the initial state and after being preloaded in a drawbead with $v=50 \mathrm{~mm} / \mathrm{s}$, a blank holder pressure of $p_{\mathrm{N}}=5 \mathrm{MPa}$ and the drawbead heights $h_{1}$ and $h_{2}$ in the Numisheet 2008 geometry. All in all, the material parameters have a standard deviation of maximum $7 \%$ compared to their average value. This is observed to be respectable for preloaded strips. This deviation was examined with a number of specimens of $n=5$. 


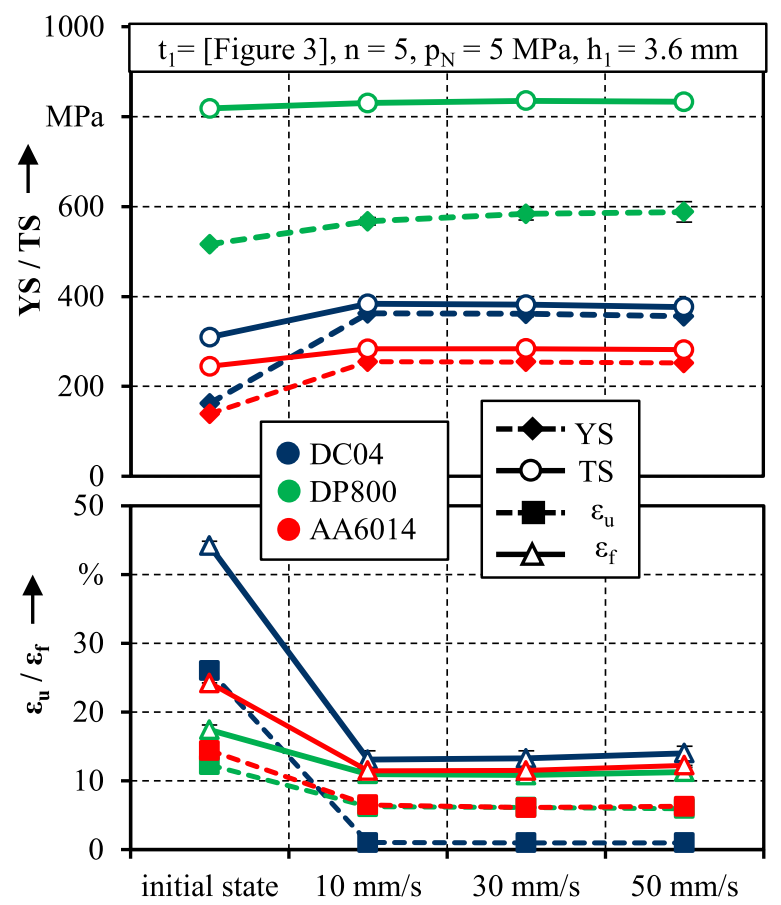

Fig. 6. Tensile test parameters after a drawbead with variation of the drawing velocity between $v=10 \mathrm{~mm} / \mathrm{s}$ and $50 \mathrm{~mm} / \mathrm{s}$ $\left(h_{1}=3.6 \mathrm{~mm}, p_{\mathrm{N}}=5 \mathrm{MPa}\right)$.

It can be observed, that for all materials a significant change is visible. In Figure 5, the fracture strain is clearly smaller for the preloaded materials. For example the fracture for DC04 occurs in the initial state at a true strain of about 0.35 . After preloading in a drawbead, the material is not able to bear more than a true strain of 0.15 . For DP800 and the aluminium alloy AA6014, similar observations are possible. Also, the maximum value of the true stress changes significantly. When comparing curves for the two different drawbead heights, an increase of stress with a higher drawbead is visible for steel material. Depending on the sheet metal, the fracture strain of variations with a drawbead $h_{2}=5.0 \mathrm{~mm}$ are smaller compared the one for the smaller drawbead $h_{1}$. The true stress-true strain curves in Figure 5 also indicate the need for a more detailed comparison of different preloading variations. Therefore, the standard material parameters of tensile tests are used to quantify occurring changes. Therefore, four parameters are chosen: the yield strength YS at $0.2 \%$ plastic strain, the tensile strength TS, the uniform elongation $\varepsilon_{u}$ and the fracture strain $\varepsilon_{f}$.

In Figure 6, detailed changes of the above mentioned parameters are shown for a blankholder pressure of $p_{\mathrm{N}}=5 \mathrm{MPa}$, a drawbead height of $h_{1}=3.6 \mathrm{~mm}$ and the variation of the drawing velocity for the different sheet metal material. The tensile strength TS for DC04 is increased by about $100 \mathrm{MPa}$ while the yield strength YS is increased by nearly $200 \mathrm{MPa}$. The uniform elongation $\varepsilon_{u}$ of DC04 decreases from about $25 \%$ to only $1 \%$, while the fracture strain is decreased from $45 \%$ to about $15 \%$. For DP800, there is only a slight increase of the tensile strength TS and yield strength YS visible. The fracture strain of

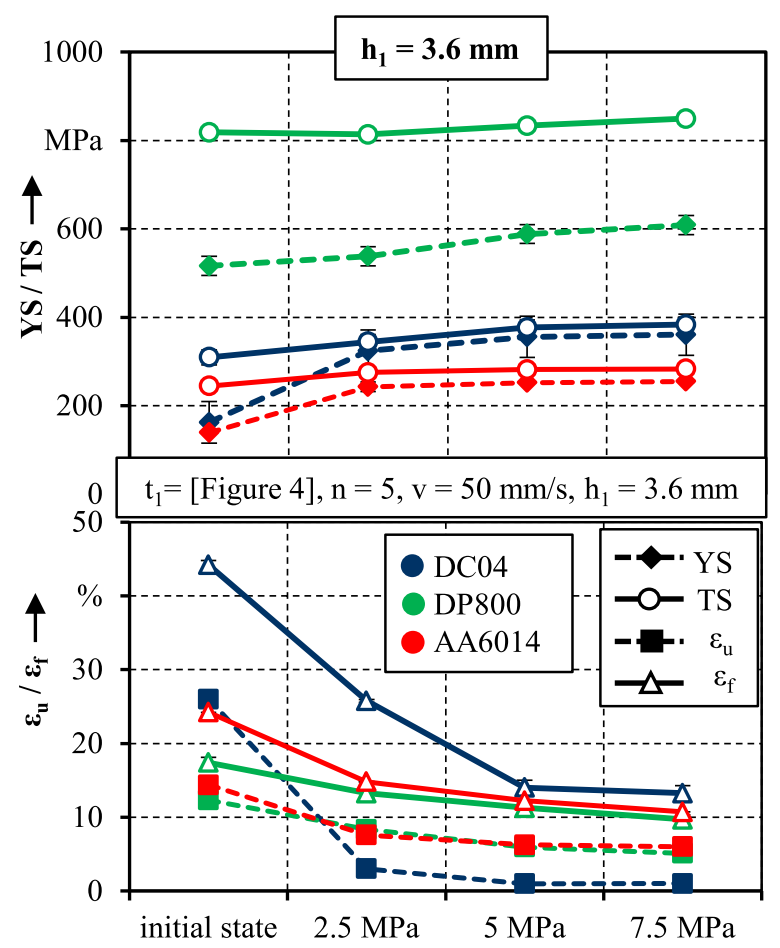

Fig. 7. Tensile test parameters after a drawbead $h_{1}$ with variation of the blankholder pressure between $p_{\mathrm{N}}=2.5 \mathrm{MPa}$ and $7.5 \mathrm{MPa}\left(h_{1}=3.6 \mathrm{~mm}, v=50 \mathrm{~mm} / \mathrm{s}\right)$.

DP800 is nearly divided in half, what is also posted for the uniform elongation $\varepsilon_{u}$. For the aluminium alloy, the yield strength YS increases significantly about $100 \mathrm{MPa}$ while the tensile strength is increased slightly. The uniform elongation $\varepsilon_{u}$, as well as the fracture strain $\varepsilon_{f}$ are reduced by over $50 \%$ after the passage with the drawbead height $h_{1}$.

For all examined materials, there is no significant change in between the material parameters when varying the drawing velocity from $10 \mathrm{~mm} / \mathrm{s}$ to $30 \mathrm{~mm} / \mathrm{s}$ and $50 \mathrm{~mm} / \mathrm{s}$. The difference in parameter for all analysed materials is in between the corresponding standard deviation. It can be followed, that the variation of the velocity in between $v=10-50 \mathrm{~mm} / \mathrm{s}$ most likely does not have any impact on the material itself, what was also expected after analysing the sheet thickness. At least the parameters do not change significantly compared to other preloaded specimens. From these results, it is expected to get the same results and conclusions for the drawbead with $h_{2}=5.0 \mathrm{~mm}$.

As the investigated materials do not show any strain rate dependency in between the analysed range, in the following examinations the maximum drawing velocity of $v=50 \mathrm{~mm} / \mathrm{s}$ will be used. Considering the variation of the blankholder pressure $p_{\mathrm{N}}$ in Figure 7 at $v=50 \mathrm{~mm} / \mathrm{s}$ and the drawbead height $h_{1}=3.6 \mathrm{~mm}$, the results are more manifold compared to the variation of the velocity before. As it can be seen for the mild steel DC04, there is a difference between the varied blankholder pressure levels. The tensile strength rises clearly with higher pressure, what also has an effect on the YS. The uniform elongation $\varepsilon_{u}$ and the fracture strain $\varepsilon_{f}$ are decreasing with higher pressure. The material parameters change between $p_{\mathrm{N}}=5.0 \mathrm{MPa}$ 


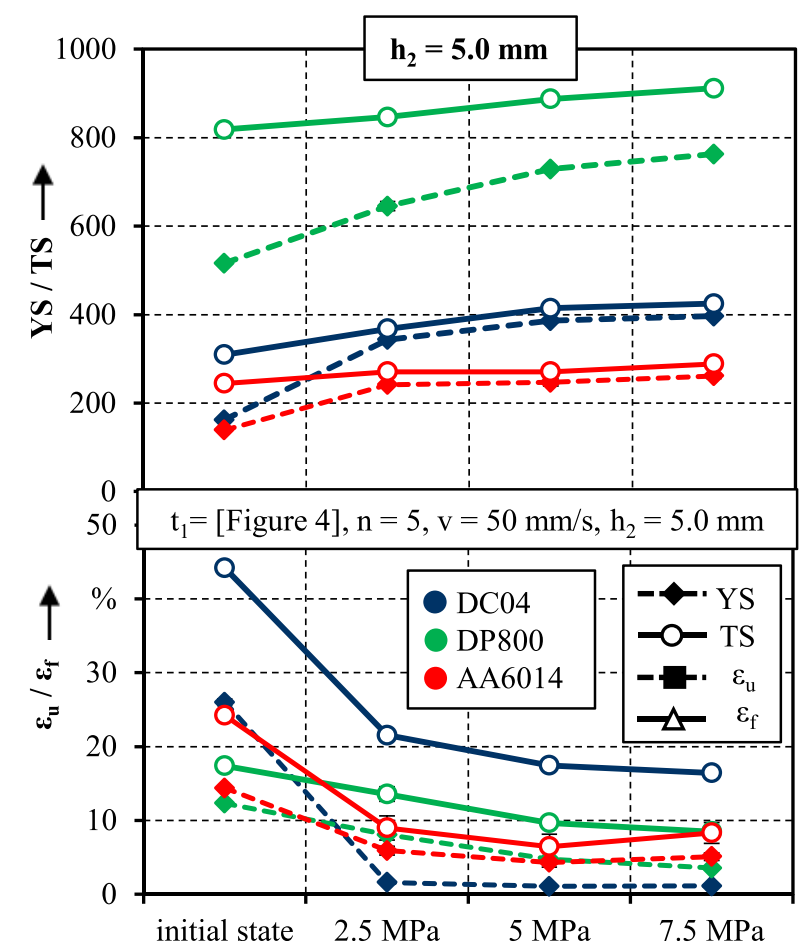

Fig. 8. Tensile test parameters after a drawbead $h_{2}$ with variation of the blankholder pressure between $p_{\mathrm{N}}=2.5 \mathrm{MPa}$ and $7.5 \mathrm{MPa}\left(h_{2}=5.0 \mathrm{~mm}, v=50 \mathrm{~mm} / \mathrm{s}\right)$.

and $7.5 \mathrm{MPa}$ more significant compared to the gradient between 2.5 MPa and 5.0 MPa. Considering DP800, similar findings can be observed. Although the tensile strength TS does not increase in the same amount compared to DC04, a higher pressure level also provides higher tensile strength levels. Looking on the strains in the preloaded specimens, a decrease is also visible for DP800.

By rising the pressure level from 2.5 MPa to $5 \mathrm{MPa}$ and further on to $7.5 \mathrm{MPa}$, the fracture strain and the uniform elongation are clearly minimized for DP800. In Figure 7, the development of YS and TS for AA6014 can nearly be compared to the ones of DC04, only without reaching the same stress levels. For AA6014, the fracture strain $\varepsilon_{\mathrm{f}}$ is decreased from $15 \%$ to about $5 \%$. For an easier comparison, in Figure 8 the variation of the blankholder pressure $p_{\mathrm{N}}$ with a constant velocity $v=50 \mathrm{~mm} / \mathrm{s}$ with the drawbead $h_{2}=5.0 \mathrm{~mm}$ can be seen. Looking at the YS, it can be analysed that a rise with using the higher drawbead is visible. Exemplarily, the YS of DP800 at $p_{\mathrm{N}}=7.5 \mathrm{MPa}$ reaches about $600 \mathrm{MPa}$ for $h_{1}=3.6 \mathrm{~mm}$, while it reaches $750 \mathrm{MPa}$ for the higher drawbead $h_{2}=5.0 \mathrm{~mm}$. For the TS of DP800, the same development is seen. AA6014 and DC04 also show an increase in the tensile strength TS and the yield strength YS, that is absolute smaller.

Looking at the strain parameters uniform elongation $\varepsilon_{u}$ and fractures strain $\varepsilon_{f}$, an overall decrease is also visible. Overall, the fracture strain of all materials is decreased slightly. As before in Figure 7 for the drawbead with $h_{1}=3.6 \mathrm{~mm}$, a saturation level appears for AA6014 and DC04 regarding the two pressures of $p_{\mathrm{N}}=5.0 \mathrm{MPa}$ and $p_{\mathrm{N}}=7.5 \mathrm{MPa}$. For an easier review of the results for the two

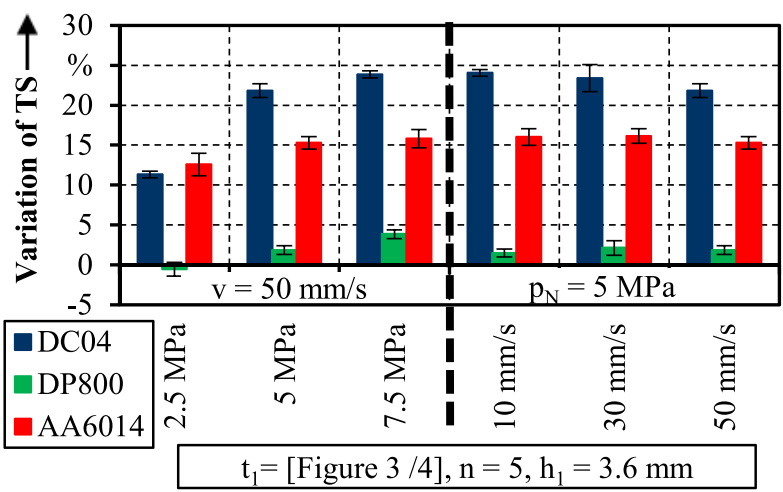

Fig. 9. Modification of the tensile strength TS in tensile tests after preloading in a drawbead passage with $h_{1}=3.6 \mathrm{~mm}$.

drawbead heights $h_{1}$ and $h_{2}$, some conclusions can be drawn. On the one hand, using a drawbead generally leads to higher TS and YS and lower $\varepsilon_{u}$ and $\varepsilon_{f}$. The rise of the blankholder pressure leads to higher values for the yield strength YS and the tensile strength TS. One the other side, this results in significantly lower values of the uniform elongation $\varepsilon_{u}$ and the fracture strain $\varepsilon_{f}$. For some occasions, saturation levels are visible, what was also mentioned.

Comparing the results for the two different drawbeads, higher levels for YS and TS were observed, whereas overall an increase in the uniform elongation $\varepsilon_{u}$ and the fracture strain $\varepsilon_{f}$ was seen. Most likely, the impact on the stress parameters was more significant.

Because the sheet metal materials DC04, DP800 and AA6014 show different behaviour in tensile tests, it is necessary to use specific values to compare them respecting their initial state.

\section{Discussion}

This section is used for a detailed examination of the results presented in the chapter before and for possible explanations for this behaviour.

\subsection{Comparison of the effects on material properties by parameter variation}

For a detailed comparison and discussion, the tensile strength TS and the fracture strain $\varepsilon_{f}$ are chosen to investigate in detail. The tensile strength TS provides an overview of maximum tolerable stresses and is therefore able to describe maximum forces and loads. The fracture strain $\varepsilon_{f}$ is used as a value for the ultimate plastic strain what is a description for failure. Failure is here considered regarding the strains and not only the stresses. The parameters analysed in Section 5 are set in relation to their initial state and the increase or decrease is given relative. Also, the standard deviation is calculated with $n=5$ specimens tested and analysed. For a better overlook, the results for all three materials are drawn into one diagram considering the variation of tensile strength TS or the fracture strain $\varepsilon_{f}$. The first analysis is given in Figure 9, where the modification of tensile strength TS can be seen in 
detail for $h_{1}=3.6 \mathrm{~mm}$ and by varying the blankholder pressure and the velocity as it was shown before in Figures 6 and 7 .

On the first hand, it is visible that the increase in tensile strength TS is higher for DC04 compared to DP800. In general, it is evident that TS for DC04 is still increased when raising the blankholder pressure. For $p_{\mathrm{N}}=7.5 \mathrm{MPa}$ and $v=50 \mathrm{~mm} / \mathrm{s}$, it is raised by $25 \%$. The TS of DP800 raises by $4 \%$, for $\mathrm{AA} 6014$ a rise of $15 \%$ is shown. One variation of the tensile tests of DP800 $\left(p_{\mathrm{N}}=2.5 \mathrm{MPa}\right.$, $v=50 \mathrm{~mm} / \mathrm{s}$ ) shows a small decrease. In practical use, it can be seen as a lack of changes in TS and in between the standard deviation.

It is also visible, that an increase of the pressure between $p_{\mathrm{N}}=2.5 \mathrm{MPa}$ and $7.5 \mathrm{MPa}$, increases the gradient of the tensile strength results. For a velocity of $v=50 \mathrm{~mm} /$ $\mathrm{s}$, the effect of $p_{\mathrm{N}}$ on TS is increased for DC04 from $11 \%$ at $p_{\mathrm{N}}=2.5 \mathrm{MPa}$ to about $21 \%$ at $p_{\mathrm{N}}=5 \mathrm{MPa}$ to over $25 \%$ at $p_{\mathrm{N}}=7.5 \mathrm{MPa}$. A small gradient of TS between $p_{\mathrm{N}}=5 \mathrm{MPa}$ and $7.5 \mathrm{MPa}$ indicates saturation by plastic deformation, what was also expected before. Regarding the results for varying the velocity for DC04, the differences are in between the standard deviations and therefore no significance is given. When looking at the high-strength steel DP800 in Figure 9, the increase of TS is only 4\% and lower compared to DC04 and AA6014. Indeed, one can also detect an increase in the tensile strength TS for a rising of the pressure $p_{\mathrm{N}}$, but only up to $4 \%$ and not to $25 \%$ like for DC04. For the variation of the velocity $\mathrm{v}$, there are no significant differences in the development of TS for DP800. For the investigation of AA6014 and a normal pressure of $p_{\mathrm{N}}=2.5 \mathrm{MPa}$, TS is raised by $12 \%$. For further rise of the blank holder pressure of $p_{\mathrm{N}}=5 \mathrm{MPa}$ up to about $15 \%$ what is also kept for 7.5 MPa. Also for AA6014, no significant change is seen in TS when varying the drawing velocity.

For Figure 9 it can be summarised in between the investigated boundaries that a rise of the blankholder pressure $p_{\mathrm{N}}$ leads to higher changes of TS with maxima up to $25 \%$ for DC04, $4 \%$ for DP800 and 15\% for AA6014. Changing the velocity between $v=10 \mathrm{~mm} / \mathrm{s}$ and $50 \mathrm{~mm} / \mathrm{s}$ does not have a significant influence on TS because it does not show any shift for these variations. DP800 shows a lower level of residual formability considering the TS compared to AA6014 and especially to DC04. After considering the changes in the applicable stresses, the effect on the maximum bearable strains is considered. In Figure 10, the influence of the varied parameters $v$ and $p_{\mathrm{N}}$ on the fracture strain $\varepsilon_{\mathrm{f}}$ with the drawbead $h_{1}$ is given.

For DC04, the fracture strain $\varepsilon_{f}$ decreases with an increasing $p_{\mathrm{N}}$. Starting with a drop of $40 \%$ at $p_{\mathrm{N}}=2.5 \mathrm{MPa}$, it drops further by over $70 \%$ for the pressure of $p_{\mathrm{N}}=5 \mathrm{MPa}$ and 7.5 MPa. Similar to the tensile strength, there is no significant gradient for DC04 between $5 \mathrm{MPa}$ and $7.5 \mathrm{MPa}$ anymore. Varying the velocity $v$ with a constant blankholder pressure of $p_{\mathrm{N}}=5 \mathrm{MPa}$, the fracture strain drops for all variations by $70 \%$ and shows no gradient in between. When looking at DP800, the drop of the fracture strain $\varepsilon_{f}$ compared to the initial state is lower than for DC04 and AA6014. For $p_{\mathrm{N}}=2.5 \mathrm{MPa}$, the fracture strain is reduced by about $20 \%$ compared to the initial samples. For $p_{\mathrm{N}}=5 \mathrm{MPa}$ and $7.5 \mathrm{MPa}$, the reduction of $\varepsilon_{f}$ is $38 \%$ and

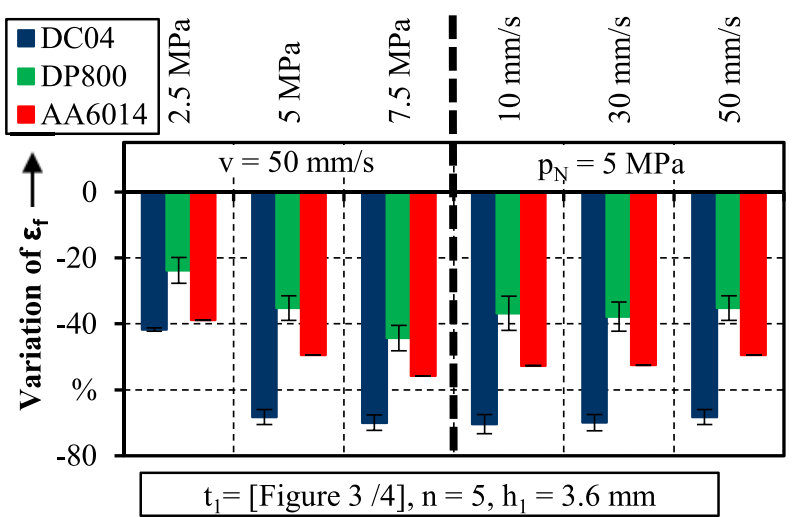

Fig. 10. Modification of the fracture strain $\varepsilon_{\mathrm{f}}$ in tensile tests after preloading in a drawbead passage with $h_{1}=3.6 \mathrm{~mm}$.

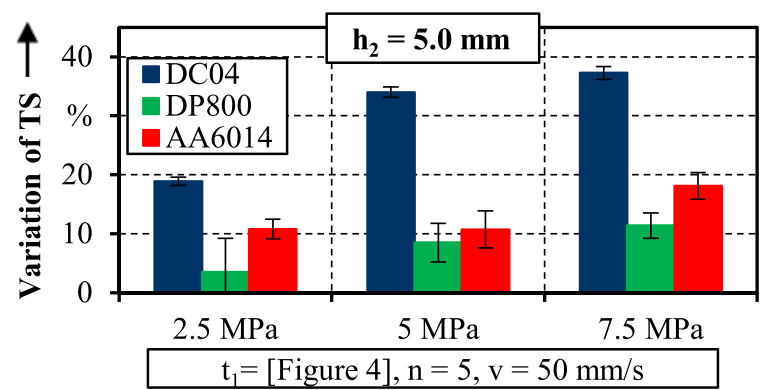

Fig. 11. Modification of the tensile strength TS in tensile tests after preloading in a drawbead passage $h_{2}=5.0 \mathrm{~mm}$.

corresponding $42 \%$. Analysing the fracture strain $\varepsilon_{f}$ of AA6014 after a drawbead passage with $h_{1}=3.6 \mathrm{~mm}$, for $p_{\mathrm{N}}=2.5 \mathrm{MPa}$ a drop by $40 \%$ is visible. For $p_{\mathrm{N}}=5 \mathrm{MPa}$ and $p_{\mathrm{N}}=7.5 \mathrm{MPa}$ a further drop of $50 \%$ and nearly $60 \%$ is shown. Like DC04 and DP800, AA6014 does not show any compelling changes for the fracture strain $\varepsilon_{f}$ when modifying the velocity $\mathrm{v}$ as it was investigated before for the tensile strength TS in Figure 9. In Figure 11, the variation of the tensile strength TS is shown for the higher drawbead $h_{2}=5.0 \mathrm{~mm}$ when the velocity is kept constant at $v=50 \mathrm{~mm} / \mathrm{s}$.

Comparable to Figure 9, the relative rise for DC04 is highest. It develops from around $19 \%$ to $30 \%$ and further on to $40 \%$ with higher blankholder pressures. For DP800, the tensile strength TS grows by over $10 \%$ for $p_{\mathrm{N}}=7.5 \mathrm{MPa}$ compared to the initial state. When using the drawbead $h_{2}=5.0 \mathrm{~mm}$ for AA6014, an increase of about $10 \%$ is seen for $p_{\mathrm{N}}=2.5 \mathrm{MPa}$ and $p_{\mathrm{N}}=5.0 \mathrm{MPa}$ and about $15 \%$ for $p_{\mathrm{N}}=7.5 \mathrm{MPa}$. Compared to the drawbead with $h_{1}=3.6 \mathrm{~mm}$ in Figure 9, this is about the doubled climb for AA6014. When looking at the fracture strain for samples after drawbeads with $h_{2}=5.0 \mathrm{~mm}$ in Figure 12, equivalent results compared to the smaller drawbead $h_{1}$ are visible.

The fracture strain after drawbead $h_{2}$, drops for DC04 by over $50 \%$ at $p_{\mathrm{N}}=2.5 \mathrm{MPa}$ to $60 \%$ at $p_{\mathrm{N}}=5 \mathrm{MPa}$ and even over $60 \%$ reduction at $p_{\mathrm{N}}=7.5 \mathrm{MPa}$. DP800 shows a similar behaviour than for the smaller drawbead $h_{1}$. The 


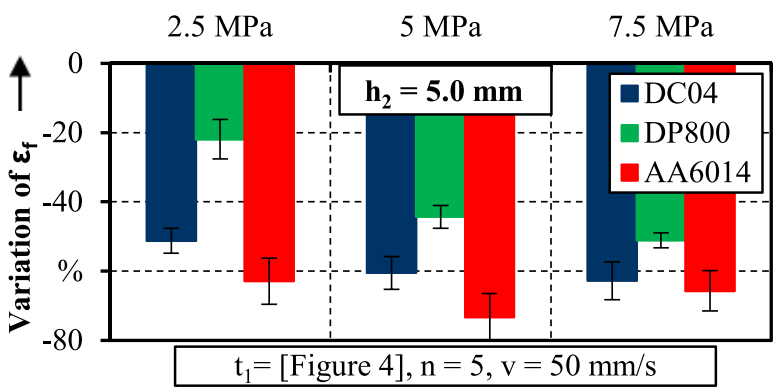

Fig. 12. Percentage modification of fracture strain in tensile tests after preloading in a drawbead passage $h_{2}=5.0 \mathrm{~mm}$.

reduction of fracture strain $\varepsilon_{f}$ at the corresponding blankholder pressure is significantly higher. Also the fracture strain of AA6014 is reduced after a drawbead. The reduction in Figure 12 is summed up to over $40 \%$ for $p_{\mathrm{N}}=2.5 \mathrm{MPa}$ and is raised to over $70 \%$ for $p_{\mathrm{N}}=5.0 \mathrm{MPa}$ $p_{\mathrm{N}}=7.5 \mathrm{MPa}$. It is remarkable, that a saturation level for the fracture strain can also be seen for AA6014 and higher pressure levels $p_{\mathrm{N}}$.

Comparing all these tensile test parameters after a drawbead and the changes to the initial state, it can be summed up that the drawing velocity $v$ has no influence in the investigated area and for this test setup. Therefore, all material parameters are significantly influenced by the variation of the blankholder pressure in the area of $p_{\mathrm{N}}=2.5 \mathrm{MPa}$ to $p_{\mathrm{N}}=7.5 \mathrm{MPa}$. This was especially shown for the tensile strength TS and the fracture strain $\varepsilon_{f}$ by comparing the analysed parameters to the initial state. All in all, a rise of the tensile strength TS by over $30 \%$ and a reduction of the fracture strain $\varepsilon_{f}$ by about $60 \%$ for the mild steel DC04 was observed.

\subsection{Detailed comparison of the influence drawbead height and blankholder pressure}

To analyse the impact of the two parameters drawbead height $h$ and blankholder pressure $p_{\mathrm{N}}$ in detail, Figures 13 and 14 will be discussed. Results are shown in detail to compare the effect of the drawbead height and the blank holder pressure easier. A modification of the tensile strength TS is shown for all materials and both drawbead heights $h_{1}$ and $h_{2}$ and the pressure levels $p_{\mathrm{N}}=5.0 \mathrm{MPa}$ and $p_{\mathrm{N}}=7.5 \mathrm{MPa}$ in Figure 13. The velocity was kept constant at $v=50 \mathrm{~mm} / \mathrm{s}$.

For DC04, a rise of the drawbead height is more significant compared to the rise from $p_{\mathrm{N}}=5 \mathrm{MPa}$ to $7.5 \mathrm{MPa}$ at a constant drawbead height. As it was described before, a saturation level at higher blankholder pressures does appear. For DP800, the overall change is smaller, but the rise because of a change in the drawbead height is more significant on TS compared to the blankholder pressure. For AA6014, findings are more complex. The change of the tensile strength TS at $p_{\mathrm{N}}=5 \mathrm{MPa}$ is higher for $h_{1}$ compared to $h_{2}$ and therefore not corresponding with other materials. Considering related standard deviations, they are nearly

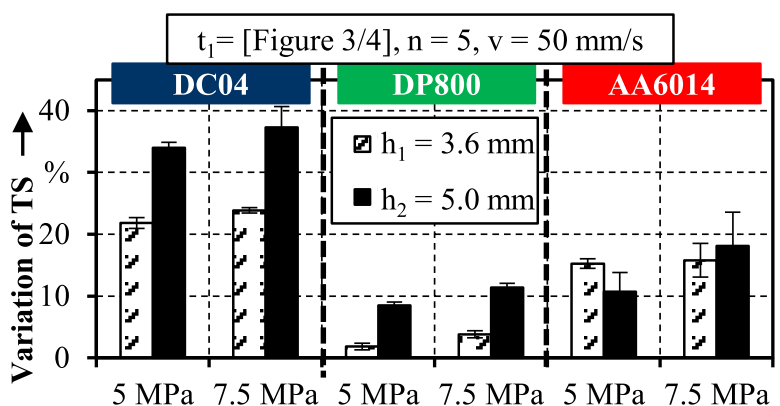

Fig. 13. Modification of the tensile strength TS in comparison for two drawbead heights and pressure levels.

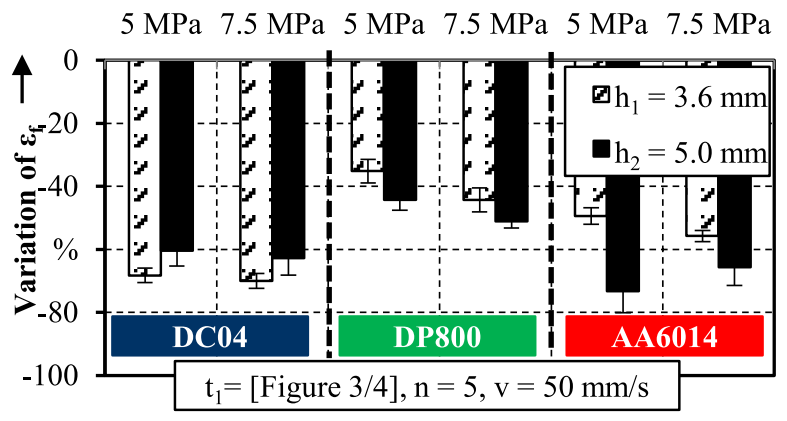

Fig. 14. Modification of the fracture strain $\varepsilon_{\mathrm{f}}$ in comparison for two drawbead heights and pressure levels.

overlapping as they also do for the pressure of $p_{\mathrm{N}}=7.5$ $\mathrm{MPa}$. A clear influence of the higher drawbead is not evident for AA6014. For DC04 and DP800, it can be summarized in general, a higher drawbead has a bigger effect compared to a change in $p_{\mathrm{N}}$ from $5 \mathrm{MPa}$ to $7.5 \mathrm{MPa}$.

In Figure 14, the modification of the fracture strain $\varepsilon_{\mathrm{f}}$ is given for the two blankholder pressure levels and the two levels of the drawbead height $h_{1}$ and $h_{2}$.

Analysing the mild steel DC04 in Figure 14, no effect for the rise from $5 \mathrm{MPa}$ to $7.5 \mathrm{MPa}$ is visible. For the drawbead height of $h_{1}=3.6 \mathrm{~mm}$, the change in fracture strain is even smaller compared to the corresponding result for $h_{2}=5.0 \mathrm{~mm}$. Both blankholder levels tend to show the same behaviour. It is also important to remark, that standard deviations are overlapping. Therefore, it can be interpreted as a saturation level with statistic deviations. For DP800, the changes compared to the initial state are visible. A lower drawbead height $h$ and a lower blankholder pressure $p_{\mathrm{N}}$ lead to bigger reductions of the fracture strain $\varepsilon_{f}$. As the standard deviations also tend to overlap, it should be only considered as a trend. AA6014 also shows a clear development from lower to higher pressure and drawbead as it was shown before for DP800. One thing is remarkable: the fracture strain modification for the drawbead $h_{2}=5.0 \mathrm{~mm}$ and the pressure $p_{\mathrm{N}}=5 \mathrm{MPa}$ is higher than the one for the $p_{\mathrm{N}}=7.5 \mathrm{MPa}$ what is not expected. Again, standard deviations are overlapping. Therefore measuring deviations or an existence of saturation could be possible.

By analysing Figures 13 and 14, it can be followed, that using higher blankholder pressures $p_{\mathrm{N}}$ and drawbeads leads to earlier fracture and higher tensile strengths compared to 
the initial state. For the steel materials DC04 and DP800, the influence of the drawbead height $h$ on TS is higher compared to the blankholder pressure. For AA6014, the influence from $p_{\mathrm{N}}$ on TS is evident, the effect of the drawbead height not. Regarding the fracture strain, a raise of the drawbead height results in earlier failure for DP800 and especially for AA6014. For DC04, the effect of the blankholder pressure on $\varepsilon_{\mathrm{f}}$ is reversed, what was already discussed. For DP800 and AA6014, the influence of higher blankholder pressures and drawbeads is seen for both investigated material parameters. As shown, the effects are also depending on the sheet metal material itself and most likely on local changes in the microstructure what will be discussed further on.

\subsection{Discussion of material behaviour}

Altogether, it is remarkable that DC04 shows higher modifications for the tensile strength and the fracture strain after being drawn through a drawbead geometry than the other two materials. Apparently, DP800 has a higher yield strength compared to the other materials, what was already discussed in the chapter Materials. Another possible explanation could be different microstructure evolutions of various steels. According to Nesterova et al. [26], DP800's microstructure evolution of the softer ferrite matrix, is mainly influenced by the hard phase (martensitic phase). This process is not happening for single phase steel like DC04 or even aluminium alloys like the AA6014. According to Nesterova et al., DP800 also shows much larger work hardening rates at lower plastic strains, which are correlating pretty well with local internal stresses. Connecting this with the analysed material parameters, next to the internal level of strain, it could be the reason for the lower fracture strain values reachable of DP800 compared to DC04.

Soares et al. [27] also examined the strain hardening behaviour of dual phase steels. They figured out, there is a two-staged strain hardening behaviour for DP800 steel. Up to true strains of 0.025 , the strain hardening exponent $\mathrm{n}$ is increasing rapidly. According to their research, this is due to a lot of mobile dislocations, which are introduced to ferrite by martensitic transformation in the production process. Afterwards, the exponent decreases slightly and comes to a constant value. As a summary, the authors of [27] remark, that this first stage is the most important for the whole forming process and responsible for the fast increase in work hardening of DP steels. This could also be an explanation for the different behaviour of the two steel grades represented by DC04 and DP800.

As pronounced before, Bressan et al. [13] investigated AA6014 and stated that pre-straining reduces the residual of failure linear connected to the preloading. The reduction was also linear connected to the pre-straining level. This can be combined to the results in Figure 13 and the rise of the tensile or yield strength when using higher drawbead geometries. The different work hardening behaviour, which is represented by the hardening exponent $n$, is one more explanation for occurring differences regarding the tensile strength TS as well as the fracture strain $\varepsilon_{f}$. Also, it needs to be considered that the introduced strain is quite different for the used materials. This could be already shown in [6] by the authors, where different strain levels were investigated by the help of an optical measurement system ARGUS (GOM GmbH) for DC04 and DP800.

For the variation of the blankholder pressure, a modification of material parameters was proved in general, while the velocity in the investigated area does have ignorable influences. Only for DC04, a small change for the yield strength YS in Figures 6 and 10 could be seen. This might be due to the fact, that the observed drawing velocities between 10 and $50 \mathrm{~mm} / \mathrm{s}$ do not lead to strain rates, where the materials show any strain-rate sensitivity regarding the material properties. Here, a detailed experimental investigation of occurring strain rates when applying different velocities would be interesting in the future.

The higher modifications for DC04 could also arise from its higher ability to deform what is seen in the initial fracture strain of nearly $\varepsilon_{f}=45 \%$. DP800, cold rolled steel with two different phases, has a lower initial fracture strain. The relative modification was still quite lower. The hardening exponent of DP800, which is about $n_{\mathrm{DP} 800}=$ 0.27 and about the double of $n_{\mathrm{DC} 04}=0.16$, also leads to a higher work hardening and consequently to lower strain levels. AA6014 has a hardening exponent of $n_{\mathrm{AA} 6014}=0.26$ and therefore quite similar to DP800. The other material parameters are closer to the ones of the mild steel DC04.

It is also known from literature, that aluminium and steel materials show different kinematic hardening behaviour. That was for example already shown by Suttner in [28]. As the drawbead provides an alternating bending with overlying tension, this special behaviour needs to be considered here. The analysed differences and also a varying texture of the three materials are further explanations for the different results that can be seen.

\section{Summary and outlook}

First of all, strip drawing tests with drawbead geometry were performed to replicate stresses and strains in a deep drawing process with drawbeads. The loads were applied to the sheet metal material of DC04, DP800 and AA6014 in a conventional drawbead of Numisheet 2008. The drawing velocity was varied in this work between $v=10 \mathrm{~mm} / \mathrm{s}$ and $50 \mathrm{~mm} / \mathrm{s}$, the blankholder pressure between $p_{\mathrm{N}}=2.5 \mathrm{MPa}$ and $7.5 \mathrm{MPa}$ and the drawbead height between $h_{1}=3.6 \mathrm{~mm}$ and $h_{2}=5.0 \mathrm{~mm}$. In the next step, those specimens were examined with a conventional uniaxial tensile test using an optical measurement system. The preloading process, which is also shown schematically in Figure 1, significantly changed material properties of sheet metal materials.

The most distinctive findings in this paper are:

- the tensile strength TS is increased by nearly $40 \%$ for DC04, $18 \%$ for AA 6014 and only by $11 \%$ for DP 800 using the higher drawbead;

- the fracture strain $\varepsilon_{f}$ is decreased by over $70 \%$ for DC04 and AA6014 and by 40\% for DP800; 
- increasing the blank holder pressure between $p_{\mathrm{N}}=2.5$ $\mathrm{MPa}$ and 7.5 MPa increases TS in general and decreases $\varepsilon_{f}$

- increasing the drawbead height from $h_{1}=3.6 \mathrm{~mm}$ to $h_{2}=5.0 \mathrm{~mm}$ in general also leads to an increase of TS and a decrease of the fracture strain $\varepsilon_{f}$. Depending on the sheet material and the parameters, the effect of the drawbead or the pressure is more significant;

- varying the drawing velocity between $v=10 \mathrm{~mm} / \mathrm{s}$ and $50 \mathrm{~mm} / \mathrm{s}$ has no significant influence on the tested parameters at all. This might be due to the fact, that investigated materials are not sensitive to the strain rates occurring between the applied velocities.

In this work, it was shown by tensile tests that drawbeads can lead to significant changes of material properties in deep drawing processes. These changes are connected to the implemented level of strain, plastification and work hardening processes. Depending on the material, the tensile strength rises while the fracture strain is decreased in dependency of the blankholder pressure and the drawbead height. For deep drawing parts, where preloaded metal is part of the final geometry, this needs to be taken into account definitely. Especially for numerical calculations of those parts, this is quite important. In the future, it would also be interesting to investigate the effect of more different drawbead geometries or sheet metal thicknesses. It is therefore also a need to examine material characteristics for other stress states than the uniaxial one after preloading. This could be for example plane strain, shearing or biaxial tests. Additional investigations of occurring strain rates when applying higher velocities would be interesting for the numerical modelling of deep drawing processes. For these processes, it is also necessary to decide which drawbead geometry and blankholder pressure is used to implement the required retention forces based on such material changes.

For the support in the research project EFB 08/114 (AiF $18328 \mathrm{~N})$, the authors would like to thank the European Research Association for Sheet Metal Working e.V. (EFB) as well as the German Federation of Industrial Research Associations "Otto von Guericke" e.V. (AiF).

\section{References}

1. M. Barthau, M. Liewald, H. Christian, J. Phys.: Conf. Ser. 896 (2017) 12040

2. H. Mohrbacher, S. Jansto, F. Siciliano, Proceedings of the International Symposium on Niobium Microalloyed Sheet Steel for Automotive Applications, Araxa, 2005, edited by S. Hashimoto (The Minerals, Metals and Materials Society TMS, Warrendale, 2006), pp. 1-23
3. W. Bleck, E. Ratte, 5. Industry Colloquium, SFB 362, edited by H. Palkowski (Technical University Clausthal, ClausthalZellerfeld, 2005), pp. 35-40

4. S.-D. Liu, S. Jiang, M. Garnett, 21st Biennial Congress of the International Deep Drawing research Group (2000) pp. 203212

5. H. Schmid, S. Suttner, M. Merklein, in Proceedings of WGP annual meeting Aachen, 2017, edited by R. H. Schmitt, G. Schuh, (Apprimus, 2017), pp. 37-42

6. H. Schmid, S. Suttner, M. Merklein, J. Phys.: Conf. Ser. 896 (2017)

7. H.S. Halkaci, M. Turkoz, M. Dilmec, Mater. Process. Technol. 214 (2014) 1638-1646

8. M. Samuel, J. Mater. Process. Technol. 122 (2002) 94-103

9. E. Silvestre, J. Mendiguren, L. Galdos, E. Sáenz de Argandoña, Int. J. Mech. Sci. 101-102 (2015) 10-20

10. S. Schreijäg, Ph.D. thesis, KIT Karlsruhe, 2013

11. M. Bloeck, in Advanced Materials in Automotive Engineering, edited by J. Rowe (Elsevier, 2012)

12. K. Drotleff, M. Liewald, IOP Conf. Ser.: Mater. Sci. Eng. 418, (2018)

13. J. Divo Bressan, M. Liewald, K. Drotleff, AIP Conf. Proc. 1896 (2017) 020027

14. K. Kumar Saxena, I. Madhumita Das, J. Mukhopadhyay, Int. J. Mater. Form 10 (2017) 221-231

15. D. Kitting et al., Key Eng. Mater. 554-557 (2013) 1252 1264

16. S.P. Keeler, D. Sc. Thesis, MIT, Cambridge, 1961

17. German Institute for standardization, DIN, DIN EN ISO 1200 4-2, 2009

18. W. Müschenborn, H.-M. Sonne, Arch. Steel Inst. 46 (1975) 597-602

19. R. Denninger, M. Liewald, M. Sindel, Key Eng. Mater. 504506 (2012) 101-106

20. A. Werber et al., Key Eng. Mater. 504-506 (2012) 71-76

21. P. Hora, in International Conference and Workshop on Numerical Simulation of 3D Sheet Metal Forming Processes, Interlaken, edited by P. Hora (ETH Zürich, Numisheet, 2008)

22. German institute for standardization, DIN, DIN EN ISO 6892-1, 2017

23. Steel Institute VDEh, Testing and Documenting Guideline for the Experimental Determination of Mechanical Properties of Steel Sheets for CAE-Calculations, 2006

24. German Association of Automotive Industry, VDA 239-300, Experimental Determination of Mechanical Properties, 2015

25. H. Schmid, M. Merklein, F. Vollertsen, T. A. Dean, Y. Qin, S. J. Yuan, MATEC Web Conf. 190 (2018) 5001

26. E.V. Nesterova, S. Bouvier, B. Bacroix, Mater. Charact. 100 (2015) 152-162

27. G.C. Soares, B.M. Gonzalez, L. de Arruda Santos, Mater. Sci. Eng. A 684 (2017) 577-585

28. S. Suttner, M. Merklein, Paris, 25th Biennial Congress of the International Deep Drawing Research Group (2014), pp. $125-130$

Cite this article as: Harald Schmid, Marion Merklein, Study of the mechanical properties of sheet metals drawn through drawbeads, Manufacturing Rev. 6, 14 (2019) 